Iranian Journal of Breast

Disease $\varepsilon \quad 2022 ; 14(1): 7-10$.
Editorial

\section{COVID-19 and Breast Cancer}

\section{Haghighat S}

Integrative Oncology and Quality of Life Department, Breast Cancer Research Center, Motamed Cancer Institute, ACECR, Tehran, Iran
The COVID-19 pandemic has adversely affected physical, mental, social, and economic aspects of people's lives worldwide over the last year. In the early days of the pandemic, major public health priorities changed toward mobilization of resources for the care of COVID-19 patients and the protection of health workers and patients from exposure to the disease. This significantly influenced all aspects of cancer control strategies including screening, diagnosis, treatment, and supportive care.

The cancer guidelines developed during the pandemic insisted on the management of urgent cases, which would naturally result in a decrease in preventive visits, screening tests, follow-up of abnormal test results, and symptom follow-ups (1). It was estimated that breast and cervix cancer screening tests had decreased by up to $94 \%$ and that 285000 breast screening tests had been missed in the United States (2).

In the chain of cancer management, delays in each step can change the outcome of the next step. A reduction in the number of screening tests could result in missing the cancer diagnosis or recurrence. Studies from different countries reflect a reduction in the number of diagnosed breast cancer cases, ranging from one-third in the Netherlands to $52 \%$ in the US $(1,3,4)$. Therefore, lower survival probability, fewer treatment options, more intensive treatment, and poor prognosis, as consequences of late diagnosis, can be expected (1).

During the COVID-19 pandemic, some breast cancer treatment guidelines were developed based on the multidisciplinary approach and regional health facilities. One of those guidelines suggests categorizing breast cancer patients into three priority levels. Priority category A consists of patients with an urgent situation that requires immediate treatment, such as breast abscess and post-operative patients with unstable clinical and oncologic conditions. This group profits from in-person visits. Patients in priority category B should be treated before the end of the pandemic. It includes newly diagnosed breast cancer cases and patients who have completed neoadjuvant therapy and should undergo surgery. Because of the non-life-threatening nature of the situation of the patients in this category, a delay of 6-12 weeks would not impact patient outcomes. Finally, patients at the priority level $\mathrm{C}$ can have their treatment postponed until the end of the pandemic, for example, those who would present for routine follow-up for benign or malignant conditions and survivorship visits (5). However, priorities may change based on the patient's situation or local health policies. Some breast cancer patients experience their survivorship during the COVID-19 pandemic, which has affected their economic, social, and psychological status. Survivors' financial situation has changed, causing concerns about palliative care costs and insurance support. 
Patients had to stay at home, which has led to social isolation and psychological stress. A survey on cancer patients aimed to assess the impact of the pandemic on health care delivery was conducted by the American Cancer Society Cancer Action Network. According to this survey, in which $52 \%$ of the participants were breast cancer survivors (6), access to supportive services during the pandemic, including physical therapy or mental health care, had decreased by $20 \%$ (1).

Although the impact of COVID-19 on cancers may be more evident in the following years, an analysis of the effect of the pandemic on breast and colorectal cancer screening and treatment has predicted an increase of $1 \%$ (or 10000 deaths) in breast and colorectal deaths over the next decade (7).

It is necessary to note that $60 \%$ of cancer research programs have also been postponed due to funding for the COVID-19 pandemic as a global priority (1). It is expected that the management of and research into breast cancer care in Iran, as one of the first countries affected by the pandemic, would have been disrupted, too. Unfortunately, no data is available regarding the impact of COVID-19 on different aspects of breast cancer in Iran. So, breast cancer burden control strategies should be considered a health policy priority through future programming and research.

Iranian Journal Breast Diseases welcomes research articles, from different disciplines, that strive to shed light on the associations between the COVID-19 pandemic and various aspects of breast cancer (prevention, diagnosis, treatment, and rehabilitation). By giving priority to publishing these articles, we would hope to take positive steps toward addressing the gaps in the current knowledge and contribute to an improved health policy at a country level. 
سخن سردبير

كوويد-19 و سرطان بستان

\begin{abstract}
شهير حقيقت
ديارتمان يُروهشى كيفيت زندگى و طب فراخير، مركز تحقيقات سرطان يستان، يزوهشكده سرطان معتمد،

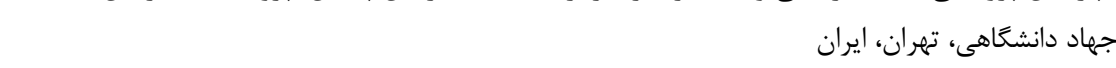

فصلنامه بيمارى هاى يستان ايران

$1 \varepsilon \cdots ! 1 \varepsilon(1): \vee-1$.

برخى دستورالعملهاى درمانى سرطان ِستان بر اساس

در سال كذشته، همه گيرى بيمارى كوويد-19 آثار مخربى بر رويكردهاى جندرشتهاى و امكانات بهداشتى و بيمارستانى

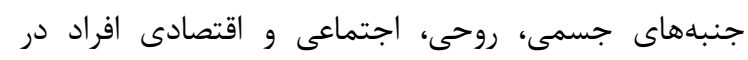
منطقهاى در طول همهگيرى تدوين شدند. مطابق يكى از اين دستورالعملها راهكارهاى مديريتى سرطان يستان در گروههاى A، B و C اولويتبندى شدند. بيماران با شرايط اورزانسى و نيازمند درمان فورى مانند آبسه يستان و افراد بعد از عمل جراحى با شرايط نايايدار بالينى و انكولوزى به

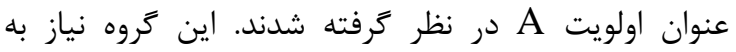
ويزيت حضورى دارند. افرادى كه به تازكى تشخيص سرطان يستان براى آنها مطرح شده است يا بيمارانى كه درمان

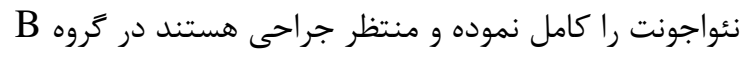
اولويتبندى شدند. افراد اين گروه بيمارانى هستند كه درمان آنها بايد قبل از اتمام همه گيرى انجام شود. با توجه به اينكه شرايط افراد اين گروه تهديدكننده زندگى نيست، يك تاخير

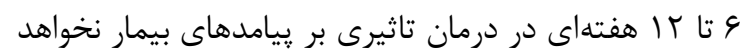

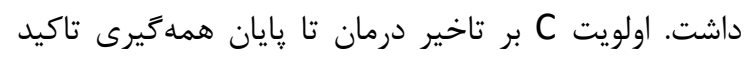
دارد، كه از آن جمله مىتوان به يیيخيرىهاى معمول براى موارد خوشخيم يا بدخيم و ويزيتهاى دورهاى بازماندگان

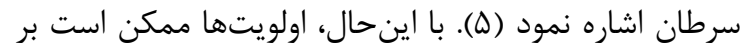
اساس شرايط بيمار يا سياستهاى بهداشتى منطقهاى تغيير نمايد. برخى مبتلايان به سرطان گِستان دوره بهبوديافتخى را در طى همه گيرى كوويد-19 تجربه مي كنند كه به لحاظ اقتصادى، اجتماعى و روانى -اجتماعى تحت تاثير قرار كرفته است. شرايط اقتصادى بيماران تغيير نموده و نترانى آنها در زمينه هزينههاى مراقبتهاى تسكينى و يوشش بيمهاى بيماري سراسر جهان داشته است. در اوايل همد كيرى، اولويتهاى اجنى اصلى بهداشت عمومى به سمت تخصيص منابع بهداشتى به اين بيمارى و زيشخيرى از مواجهه كادر درمان و بيماران

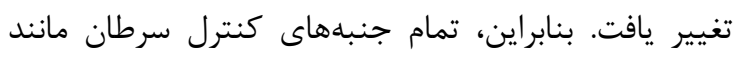

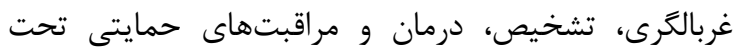
أتأثير قرار گرفتند.

دستورالعملهاى منتشر شده در طى همهَيرى كوويد-19

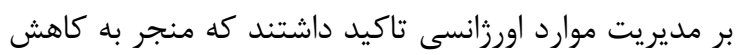

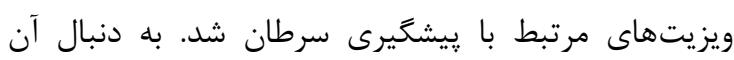
تستهاى غربالكرى و ريخيرى موارد غيرنرمال و علائم نيز كاهش يافت (1). بر اساس مطالعه انجام شده در آمريكا، تعداد تستهاى غربالگرى سرطان קستان و دهانه رحم تا

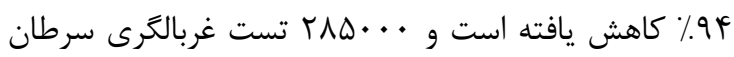

يستان نيز انجام نشده است (Y). در زنجيره مديريت سرطان، تاخير در هر مرحله مىتواند تاخير در يُيامدهاى مرحله بعدى را به همراه داشته باشد. كاهش اقدامات تشخيص زودرس مىتواند منجر به عدم تشخيص سرطان يا عود آن شود. مطالعات انجام شده در كشورهاى مختلف، نشان دهندهى كاهش ميزان تشخيص

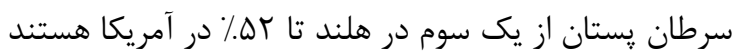

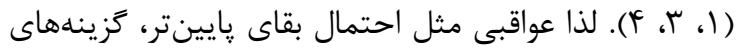

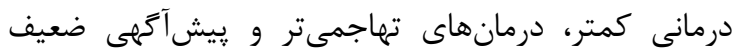
بيمارى دور از انتظار نيست (1). 
عنوان يك اولويت جهانى به تعويق افتـاده اسـت (1). مختـل شدن مديريت و تحقيقات مرتبط با سرطان يستان در ايـران، به عنوان يكى از اولين كشورهايى كه تحت تاثير اين بيمارى همه گير قرار گرفته است، دور از انتظار نمى بـاشــد. متأسـفانه،

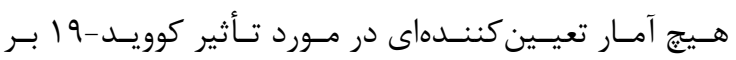

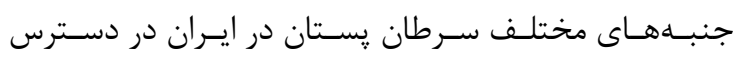
نيست. بنابراين، لازم اسـت راهكارهـاى كنتـــل بـار سـرطان يستان از طريق برنامهريزى و يـزروهش هـاى آتـى در اولويست سياستهاى بهداشتى كشور قرار گيرند.

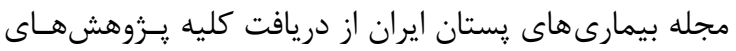

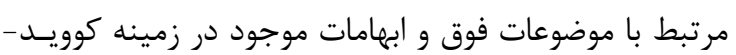

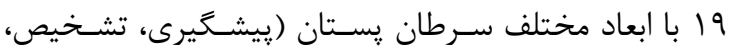
درمان و بازتوانى) استقبال مىنمايد. با اولويت دادن جاب إين تحقيقات اميدواريم قدمى مـوثر در آشـكار شـدن ارتباطـات

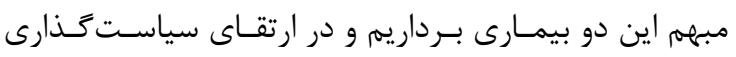
بهداشتى كشور سهيم باشيم.

\section{References}

1. American Cancer Society. Cancer Facts \& Figures 2021, Special Section: COVID-19 and Cancer: American Cancer Society; 2021. Available from: https://www.cancer.org/content/dam/cancerorg/research/cancer-facts-andstatistics/annual-cancer-facts-andfigures/2021/special-section-covid19-andcancer-2021.pdf.

2. Mast C, del Rio AM. Delayed cancer screenings-a second look. Epic Health Research Network. 2020.

3. Kaufman HW, Chen Z, Niles J, Fesko Y. Changes in the number of US patients with newly identified cancer before and during the coronavirus disease 2019 (COVID-19) pandemic. JAMA network open. 2020;3(8):e2017267-e.

4. The Netherlands Cancer Registry. Fewer breast and colorectal cancer diagnoses due to the COVID-19 crisis in the Netherlands 2021.

$$
\begin{aligned}
& \text { افزايش يافته است. بازماندكان سرطان مجبور به ماندن در } \\
& \text { خانه شدهاند، كه اين امر مىتواند به انزواى اجتماعى و ايجاد } \\
& \text { استرس روانى در آنها منجر شود. يك مطالعهى ييمايشى از } \\
& \text { سوى انجمن سرطان آمريكا با هدف بررسى تاثير همهَيرى } \\
& \text { بر ارائه مراقبتهاى بهداشتى به بيماران مبتلا به سرطان }
\end{aligned}
$$

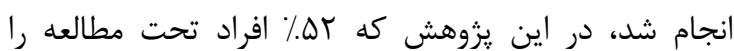

$$
\begin{aligned}
& \text { r. مبتلايان به سرطان קستان تشكيل مىدادند، كاهش } \\
& \text { درصدى دسترسى به سرويسهاى حمايتى از جمله } \\
& \text { فيزيوترايى و مراقبتهاى بهداشت روان كزارش شد ( (، ؟). }
\end{aligned}
$$

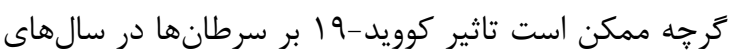

$$
\begin{aligned}
& \text { ريشرو بيشتر مشهود باشد، با تحليل تاثير كوويد-19 بر } \\
& \text { غربالكرى و درمان سرطان پستان و كولوركتال افزايش يك } \\
& \text { درصد يا . . . . إ مورد مرى ناشى از اين دو سرطان در دهـ } \\
& \text { آينده بيش بينى شده است (V) } \\
& \text { لازم به ذكر است كه . ٪\% برنامه هاى تحقيقاتى سـرطان نيـز }
\end{aligned}
$$

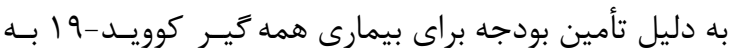

Available from: https://iknl.nl/en/news/fewerbreast-and-colorectal-cancer-diagnoses-due-t.

5. Dietz JR, Moran MS, Isakoff SJ, Kurtzman SH, Willey SC, Burstein HJ, et al. Recommendations for prioritization, treatment, and triage of breast cancer patients during the COVID-19 pandemic. the COVID19 pandemic breast cancer consortium. Springer; 2020.

6. American Cancer Society Cancer Action Network. COVID-19 Pandemic Ongoing Impact on Cancer Patients and Survivors, Survey Findings Summary: American Cancer Society Cancer Action Network; 2021. Available from: https://www.fightcancer.org/covid-19pandemic-ongoing-impact-cancer-patientsand-survivors.

7. Sharpless NE. COVID-19 and cancer. American Association for the Advancement of Science; 2020. 